\title{
Contexto socioespacial de vítimas de homicídio doloso em uma capital do nordeste brasileiro
}

\section{The socio-spatial context of intentional homicide victims in a capital of Brazilian Northeast}

\author{
Alline Oliveira do Nascimento Veloso ${ }^{1}$ (D), Kaio Keomma Aires Silva Medeiros ${ }^{2}$ (D), \\ Rackynelly Alves Sarmento Soares ${ }^{3}$ (D), Francilene Jane Rodrigues Pereira ${ }^{4}$ (D), \\ Cícero Fidelis da Silva Neto ${ }^{5}$ (D) Alessandro Leite Cavalcanti ${ }^{1}$ (D) \\ ${ }^{1}$ Programa de Pós-graduação em Saúde Pública (PPGSP), Universidade Estadual da Paraíba (UEPB) - Campina Grande (PB), Brasil. \\ ${ }^{2}$ Faculdade de Saúde Pública, Universidade de São Paulo (USP) - São Paulo (SP), Brasil. \\ ${ }^{3}$ Núcleo de Estudos em Saúde Coletiva (NESC), Universidade Federal da Paraíba (UFPB) - João Pessoa (PB), Brasil. \\ ${ }^{4}$ Universidade Federal da Paraíba (UFPB), Programa de Pós-graduação em Modelos de decisão em Saúde (PPGMDS) - João \\ Pessoa (PB), Brasil. \\ ${ }^{5}$ Instituto Nacional do Semiárido (INSA), Universidade Federal de Campina Grande (UFCG) - Campina Grande (PB), Brasil.
}

Como citar: Veloso AON, Medeiros KKAS, Soares RAS, Pereira FJR, Silva Neto CF, Cavalcanti AL. Contexto socioespacial de vítimas de homicídio doloso em uma capital do nordeste brasileiro. Cad Saúde Colet, 2020;28(2):180-188. https://doi. org/10.1590/1414-462X202028020034

\section{Resumo}

Introdução: O homicídio, para além de um problema de saúde pública, é também revelador de um complexo contexto de desigualdade social, que impera nas capitais e grandes cidades do Brasil. Objetivo: Analisar o contexto socioespacial de vítimas de homicídio doloso em uma capital do nordeste brasileiro. Método: Estudo ecológico, de base documental, com abordagem quantitativa, realizado em João Pessoa, no estado da Paraíba, no Brasil, em 2015. Consideraram-se 369 vítimas de homicídio doloso. Os dados foram analisados à luz da estatística descritiva e da geografia espacial. Resultados: As vítimas de homicídio doloso eram predominantemente homens, adultos jovens, não brancos, solteiros e com menos de sete anos de estudo. Ademais, verificou-se sobreposição, em grande medida, das áreas em que residiam aqueles indivíduos com as áreas de piores condições socioeconômicas. Conclusão: O homicídio repercute substancialmente no quadro epidemiológico, porquanto, para além de sua característica letal, as questões que o circunscrevem, em que figura, de forma importante, são questões sociais complexas, amplas e de difícil modificação no curto prazo. Palavras-chave: mortalidade; homicídio; análise espacial; classe social.

\begin{abstract}
Background: The homicide, besides being a public health problem, also reveals a complex context of social inequality that prevails in capitals and larges cities of Brazil. Objective: The objective of this study was to analyze the socio-spatial context of intentional homicide victims in a capital of Brazilian Northeast. Method: An ecological and documentary based study with a quantitative approach was carried out in João Pessoa, state of Paraíba, Brazil, in 2015, which considered 369 victims of homicide. Data analysis was carried out in light of descriptive statistics and spatial analysis. Results: Victims of malice murder were predominantly male, young adults, non-white, singles, and less than seven years of studies. In addition, there was overlap, to a large extent of the areas where the victims of malice murder resided, with the map of the areas with the worst socioeconomic conditions. Conclusion: Homicide has a substantial repercussion on the epidemiological context, in addition to its lethal characteristic. The issues surrounding them, in which important complex social issues appear, are broad and difficult to change in the short term.
\end{abstract}

Keywords: mortality; homicide; spatial analysis; social class.

Trabalho realizado na Delegacia de Crimes Contra a Pessoa da Polícia Civil - João Pessoa (PB), Brasil.

Correspondência: Alline Oliveira do Nascimento Veloso. E-mail: lilionvjp@gmail.com

Fonte de financiamento: nenhuma.

Conflito de interesses: nada a declarar.

Recebido em: Mar. 15, 2018. Aprovado em: Ago. 04, 2019
Este é um artigo publicado em acesso aberto (Open Access) sob a licença Creative Commons Attribution, que permite uso, distribuição e reprodução em qualquer meio, sem restrições desde que o trabalho original seja corretamente citado. 


\section{INTRODUÇÃO}

O homicídio doloso, violência interpessoal de causa intencional e com desfecho letal, é um fenômeno global, que tem apresentado tendência crescente em países da América Latina, sobretudo no Brasil, no qual já desponta como principal causa de morte por fatores externos, constituindo um importante problema de saúde pública, principalmente em capitais, onde se tem naturalizado ${ }^{1-6}$.

Com efeito, em 2014, foram registrados 59.681 homicídios dolosos no país e, no estado da Paraíba, no nordeste brasileiro, região que tem apresentado, sistematicamente, elevação nos citados agravos, foram reportados 1.551 homicídios, 39,4 para cada 100 mil habitantes, com destaque para a sua capital, João Pessoa, comportando pouco menos de um terço de todos os óbitos do estado ${ }^{3}$. Observa-se, porém, que, embora ainda que necessitem de maior difusão em Saúde Pública, os estudos que buscam explicar o contexto desse tipo de agravo na cidade, sobretudo em relação às características socioespaciais em que se insere, são fundamentais ao desenvolvimento de políticas públicas no setor e para além dele.

Embora há muito se conheça que os homicídios dolosos resultam, em linhas gerais, da combinação de uma multiplicidade de fatores, quer individuais, referentes às vítimas e aos agressores, quer institucionais e estruturais, externas a elas, portanto, e que, nas localidades com altas taxas de ocorrência, é notória a concentração de uma população em precárias condições socioeconômicas, bem como o aumento do desemprego e do trabalho informal, o crime organizado representado pelo tráfico de drogas e pelo comércio ilegal de armas, torna-se forçoso, não obstante, ampliar o desenvolvimento de estudos como este enfoque ${ }^{7-9}$.

Se, por um lado, o incremento em estudos com a temática de homicídios dolosos pode contribuir para reforçar a intrínseca relação existente entre estes e os aspectos socioeconômicos amplamente conhecidos, por outro lado, pode permitir a visualização de diferentes contextos e associações. Nessa perspectiva, o geoprocessamento pode operar no sentido de trazer esses novos enfoques, uma vez que tem potencial de não apenas identificar localidades com risco elevado do agravo em questão, mas também ser útil como uma importante ferramenta para acompanhamento de populações em risco ${ }^{10}$.

Ademais, o geoprocessamento pode contribuir enormemente para a avaliação de concentrações de casos de homicídios dolosos, identificando os fatores relacionados. Isso é possível, porque, em geral, a representação de eventos como estes é realizada na forma de pontos, usualmente utilizados na elaboração de mapas na área de Saúde Pública, com a hipótese de que fatores determinantes expliquem a distribuição apresentada ${ }^{11}$. Não por acaso, ressalta-se a utilização de técnicas como esta para identificar aglomerações de óbitos em diferentes localidades, nacional e internacionalmente ${ }^{12,13}$.

Para além do ineditismo no cenário em que foi realizado, estudos como este mostram-se pertinentes ainda pelo contributo teórico, dada a discussão a que se propõem. E, em virtude da notória aplicabilidade prática, considerando que a maior compreensão destes agravos pode contribuir para além do contexto da segurança pública, mas sobretudo para o delineamento de políticas intersetoriais que envolvam diferentes atores políticos, especialmente no contexto de crise econômica e de austeridade fiscal em voga, que certamente impactará mais ainda a realidade em tela nas próximas décadas.

Assim, partindo-se do pressuposto de que os homicídios dolosos se distribuem desigualmente entre as diferentes localidades, com maior peso nas áreas com piores indicadores socioeconômicos, objetivou-se, com o presente estudo, analisar o contexto socioespacial das vítimas destes agravos em uma capital do nordeste brasileiro e sua relação com aglomerados subnormais e variáveis socioeconômicas.

\section{MÉTODO}

Estudo ecológico, documental e com abordagem quantitativa, realizado na cidade de João Pessoa, capital do estado da Paraíba, no Brasil, em 2014.

A base para o estudo foram todos os inquéritos policiais realizados pela Polícia Civil, que estão concentrados na Delegacia de Crimes contra a Pessoa. Esses registros constituem 
instrumentos formais de investigação e representam o conjunto de diligências produzidas por Investigadores de Polícia e Peritos Criminais, são organizados pelo Escrivão de Polícia e presididos pelo Delegado de Polícia", com o objetivo de apurar o fato criminoso e descobrir sua autoria ${ }^{14}$.

Foi contabilizado um total de 424 vítimas de homicídios dolosos, no ano do presente estudo, mas foram levados em consideração 369 casos (87\%), que atendiam aos critérios de elegibilidade: possuir inquérito adequadamente preenchido e local de residência da vítima na própria cidade, cenário do presente estudo. Foram excluídos, portanto, 55 (13\%), que correspondiam aos inquéritos de vítimas que residiam em outra localidade e/ou nos quais não constava o endereço de residência.

Após autorização institucional, apresentação da proposta de pesquisa no cenário de estudo, procedeu-se à revisão dos inquéritos selecionados, a fim de coletar dados sobre as variáveis sexo, faixa etária, estado civil, cor/raça, escolaridade e local de residência. Estas, posteriormente, foram tabuladas e analisadas a partir da estatística descritiva, calculando-se médias, medianas e desvio padrão. Adicionalmente, com auxílio da estimativa Kernel, analisou-se o padrão de distribuição espacial das residências das vítimas de homicídios dolosos, tendo procedido uma representação gráfica a partir de cor e tonalidade, de modo a permitir a visualização de Hot Spots ou áreas quentes, que representam aglomerações daquelas vítimas, os denominados clusters $^{15}$.

Foi criada, em gráfico, uma superfície contínua de risco, após a distribuição espacial das residências das vítimas de homicídios dolosos previamente geolocalizada, com auxílio do Sistema de Informações Geográficas na versão 2.14.3 Essen, licenciado sob a General Public License, um projeto da Open Source Geospatial Fondation (OSGeo), a partir do MMQGIS, um conjunto de plug-ins na linguagem de programação Python capaz de manipular camadas de mapas vetoriais no QGIS, software desenvolvido para esta finalidade.

Desse modo, pôde-se visualizar a origem das vítimas de homicídios dolosos, a partir do local de residência, com indicação em cores e tonalidades diferentes no mapa. Para efeito deste estudo, convencionou-se utilizar o vermelho para demarcar os locais com maior frequência, o azul para indicar aqueles com baixa frequência e o amarelo para representar uma transição entre as duas condições acima descritas. Para as áreas frequência zero, isto é, sem ocorrências, não se utilizaram cores.

Ademais, a fim de identificar se há relação entre o local das residências das vítimas de homicídios com áreas menos favorecidas socioeconomicamente e, portanto, de maior vulnerabilidade, o mapa de distribuição espacial daqueles indivíduos foi sobreposto a um mapa de aglomerados subnormais da cidade, disponibilizados pela sua Diretoria de Geoprocessamento, os quais representam áreas com carência de serviços públicos essenciais, tais como coleta de lixo, rede de esgoto, rede de água, energia elétrica e iluminação pública ${ }^{16}$.

Por fim, os bairros com vítimas de homicídios dolosos foram agrupados (Grupo 1), assim como aqueles em que não houve vítimas de homicídios dolosos (Grupo 2), e a totalidade dos bairros que compõem a cidade, que serviu como cenário do presente estudo, foram avaliados quanto às principais características socioeconômicas relacionadas a educação, renda e saneamento, como a média de analfabetos, de rendimento mensal e de domicílios não saneados, informações estas disponibilizadas pelo IBGE, tal como procedido em estudos sobre a temática em tela ${ }^{17,18}$.

Por questões ético-legais, a pesquisa foi realizada em observância aos princípios e diretrizes apontados na Resolução № 466 de 2012 do Conselho Nacional de Saúde ${ }^{19}$, sendo registrada na Plataforma Brasil e aprovada pelo Comitê de Ética em Pesquisa da Universidade Estadual da Paraíba (CAAE n 53324316.7.00005187).

\section{RESULTADOS}

Na Tabela 1, apresenta-se a distribuição de vítimas de homicídio doloso a partir de variáveis sociodemográficas e pode-se constatar uma população de maioria masculina ( $n=342-92,7 \%)$, adultos jovens de até 25 anos ( $n=198-53,7 \%)$, não brancos $(n=359-97,3 \%)$ e com até sete anos de estudo ( $n=248-67,2 \%)$, de baixa escolaridade, portanto. 
Tabela 1. Distribuição das vítimas de homicídio doloso a partir de variáveis sociodemográficas. João Pessoa - PB, 2014

\begin{tabular}{|c|c|c|c|}
\hline & áveis & $\mathbf{N}$ & $\%$ \\
\hline \multirow{2}{*}{ Sexo } & Masculino & 342 & 92,7 \\
\hline & Feminino & 27 & 7,3 \\
\hline \multirow{2}{*}{ Faixa Etária* } & $\leq 25$ anos & 198 & 53,7 \\
\hline & $>25$ anos & 171 & 46,3 \\
\hline \multirow{2}{*}{ Estado Civil } & Sem companheiro (a) & 255 & 69,1 \\
\hline & Com companheiro (a) & 114 & 30,9 \\
\hline \multirow{2}{*}{ Cor/Raça } & Não branco & 359 & 97,3 \\
\hline & Branco & 10 & 2,7 \\
\hline \multirow{2}{*}{ Escolaridade } & $\leq 7$ anos de estudo & 248 & 67,2 \\
\hline & 8 anos ou mais & 121 & 32,8 \\
\hline
\end{tabular}

Legenda: *Variável dicotomizada com base na média. N: número de indivíduos. Fonte: Dados da pesquisa

Em seguida, na Figura 1, apresenta-se, por meio da geolocalização, o padrão de distribuição espacial das residências das vítimas de homicídio doloso, considerando que o vermelho demarca os locais com maior frequência, o azul indica baixa frequência e a cor amarela representa uma transição entre as duas condições acima descritas, lembrando-se de que, para as áreas com frequência zero, não se utilizaram cores.

Conforme apresentado, os locais com maior aglomerado de residências das vítimas de homicídio doloso pertencem significativamente aos bairros da zona norte (Alto do Céu, Mandacaru, Jardim Treze de Maio), da zona sul (Mangabeira, Grotão, Gramame) e da zona oeste (Cristo, Cruz das Armas, Oitizeiro, Ilha do Bispo e Varjão), dos quais provinham 75,8\% daqueles indivíduos.

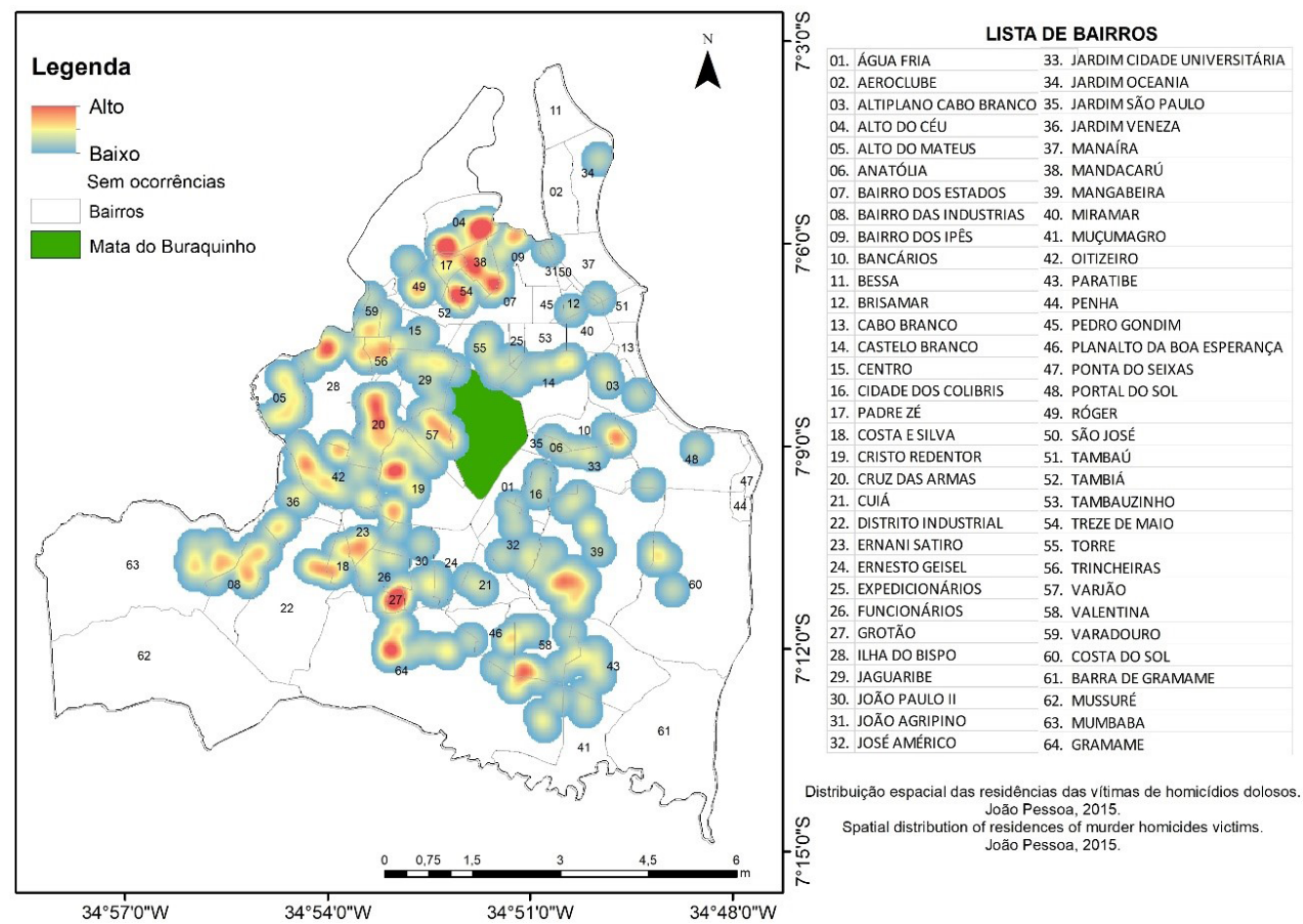

Figura 1. Distribuição espacial das residências das vítimas de homicídios dolosos. João Pessoa - PB, 2014 
A fim de identificar se há relação entre o local das residências das vítimas de homicídio doloso com áreas menos favorecidas socioeconomicamente, o mapa de distribuição espacial das primeiras, anteriormente apresentado, foi sobreposto a um mapa de aglomerados subnormais da cidade, em linha preta, conforme demonstrado na Figura 2, verificando-se que, de um modo geral, ambos os mapas coincidem em $44 \%$.

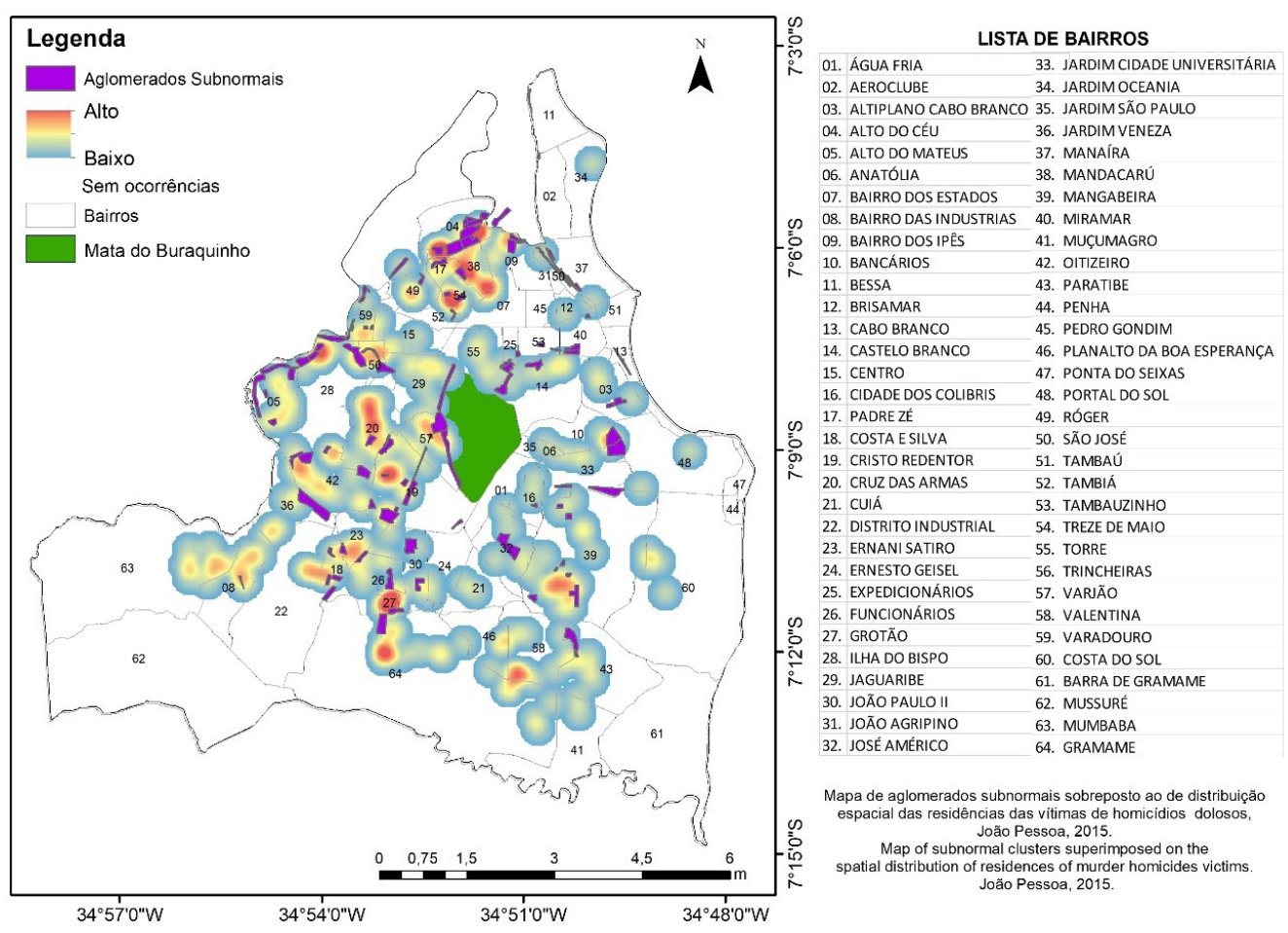

Figura 2. Mapa de aglomerados subnormais sobreposto ao de distribuição espacial das residências das vítimas de homicídios dolosos. João Pessoa - PB, 2014

Por fim, conforme demostrado na Tabela 2, o grupo de bairros com alta frequência de vítimas de homicídios (Grupo 1) apresentou piores condições socioeconômicas relacionadas a educação, renda e saneamento - considerando percentual de analfabetos e de domicílios não saneados, e rendimento médio mensal dos moradores - quando comparado com os bairros onde não houve registro de homicídios (Grupo 2) e com a média da cidade, que serviu como cenário do presente estudo.

Tabela 2. Distribuição de residências das vítimas de homicídios dolosos em recortes geográficos segundo analfabetismo, média de rendimentos e ausência de saneamento. João Pessoa - PB, 2014

\begin{tabular}{|c|c|c|c|}
\hline \multirow[b]{2}{*}{ Recortes geográficos } & \multicolumn{3}{|c|}{ Características Socioeconômicas } \\
\hline & Analfabetismo $(\%)^{(1)}$ & Rendimentos (R\$) ${ }^{(2)}$ & $\begin{array}{c}\text { Residências não } \\
\text { saneadas }(\%)^{(3)}\end{array}$ \\
\hline Bairros do Grupo $1 *$ & 13,0 & 462,50 & 47,4 \\
\hline Bairros do Grupo $2^{* *}$ & 4,9 & $1.722,80$ & 22,7 \\
\hline Todos os bairros & 9,0 & 903,78 & 43,4 \\
\hline
\end{tabular}




\section{DISCUSSÃO}

A correlação espacial entre localidades com piores condições socioeconômicas e, portanto, de maior vulnerabilidade, e aquelas com expressiva ocorrência de homicídios dolosos é inconteste, sobretudo em países da América Latina, como o Brasil20-22.

Não por acaso, pois, sabe-se que, no nordeste brasileiro, região onde os homicídios dolosos têm sido reportados em proporções cada vez mais elevadas, é expressivo o contingente de indivíduos e famílias que vivem em contextos de precariedade socioeconômica, fato que tem se tornado cada vez mais evidente, sobretudo porque o crescimento populacional dos seus centros urbanos, principalmente nas capitais, não tem sido acompanhado por iniciativas que proveriam o mínimo de cidadania para muitos dos seus habitantes ${ }^{3,19}$.

Destarte, a realidade socioeconômica das vítimas de homicídio doloso verificada no presente estudo, o qual considera a realidade de João Pessoa, importante capital do nordeste brasileiro, reforça, pelo menos em parte, aquilo que ora foi exposto e é semelhante ao encontrado em outras capitais da região, como em Maceió, no estado de Alagoas, e revela uma maior prevalência dos agravos em tela, em negros, adultos jovens e de baixa escolaridade ${ }^{1,5,23}$.

Ainda que os indivíduos mais jovens, de um modo geral, tenham sistematicamente apresentado maiores riscos de mortalidade por causas externas - acidentes e violência - e, particularmente, por homicídios dolosos, crê-se que a distribuição, nesta população do agravo em tela, não se dê homogeneamente. Com isso, aspectos, como escolaridade, mas principalmente raça/cor, parecem figurar como de grande importância, em termos de determinação social, realidade que, embora amplamente conhecida e debatida, continua a demandar importantes reflexões, sobretudo pelo grau de naturalização a que chegou ${ }^{3}$, conforme se aponta na literatura.

Sobre isso, um estudo que analisou os homicídios brasileiros em quase uma década, entre 2000 e 2009, verificou que aspectos relacionados a escolaridade, assim como a raça/cor, podem ser fatores concorrentes para maior vitimização por homicídios dolosos ${ }^{22}$, fatores também discutidos em análise realizada em outro estudo ${ }^{24}$. No entanto, segundo o que concluem os seus autores, mesmo considerando os mais e os menos escolarizados, aqueles agravos foram mais incidentes entre indivíduos não brancos, quando comparados com os brancos, e sugere, portanto, que este aspecto explica parte importante da sua ocorrência.

Para além de raça/cor, conforme colocado, condições socioeconômicas desvantajosas podem contribuir consideravelmente para a ocorrência de homicídios dolosos e muitas destas estão relacionadas com os próprios espaços urbanos ocupados pelas vítimas, que, em geral, são precariamente saneados e tem moradores analfabetos e de baixa renda. Dessa forma, não com surpresa, quando comparados os mapas dos locais de residência das vítimas e de aglomerados subnormais, as favelas e áreas periféricas, conforme realizado neste estudo, demonstrou-se que ambos os mapas, em grande medida, se sobrepõem.

Assim, conforme apontam os resultados do presente estudo, o grupo de bairros com alta frequência de vítimas de homicídios éjustamente aquele em piores condições socioeconômicas, relacionadas também a renda e saneamento - considerando rendimento médio mensal dos moradores e percentual de domicílios não saneados - quando comparado com os bairros onde não houve registro de homicídios e com a média da cidade de João Pessoa, que serviu como cenário do presente estudo.

Estudos ecológicos têm utilizado a estatística espacial para mapear áreas de risco, bem como para testar a relação entre indicadores socioeconômicos e as taxas de homicídios ${ }^{1,21}$. Assim, têm concluído que a incidência destes agravos nos arredores dos chamados aglomerados subnormais, as favelas e áreas periféricas, é consideravelmente maior, quando comparada com a incidência em outras localidades das cidades ${ }^{2,18,25}$. Um estudo, em particular, realizado na cidade de Fortaleza, capital do Ceará, também no nordeste brasileiro, identificou uma forte correlação espacial entre o local de ocorrência dos homicídios e a existência destes espaços nas proximidades ${ }^{15}$.

Nas grandes cidades, os bairros dentro das citadas áreas subnormais, embora não representem uma regra, em geral são muito povoados e, nestas condições, mostram-se mais susceptíveis a agravos, como os homicídios dolosos. Paradoxalmente, entretanto, embora 
tendam a demandar um maior quantitativo de equipamentos e insumos que, conforme disposto na literatura ${ }^{26}$, poderiam suprir as demandas de saúde, trabalho, lazer, educação, segurança e demais direitos que deveriam ser-lhes garantidos, crê-se que mais negligenciados por essas imprescindíveis iniciativas parecem estar, agravando a questão.

Nesse contexto, os autores de um estudo realizado na cidade brasileira de Cascavel, no estado do Paraná, sobre espaço urbano e criminalidade violenta, concluíram que os cenários onde há sobreposição de carências potencializam a ocorrência de conflitos violentos que resultaram em morte, como ocorre no caso específico dos homicídios dolosos ${ }^{27}$. Crê-se que, em se tratando de capitais ou grandes cidades brasileiras, o contexto em tela tende a se agravar, sobretudo quando considerado que o crescimento urbano acelerado e não planejado ainda é uma realidade, e que, na maioria das vezes, traz consigo diversos problemas estruturais, sociais, ambientais e de saúde, que são refletidos nos altos índices de pobreza, desigualdades e violência que acometem diferentes populações ${ }^{28}$.

Nesse contexto, acredita-se que, nas capitais e nas grandes cidades, os homicídios dolosos encontram-se extremamente concentrados em áreas ocupadas por populações de baixa renda e caracterizadas por pouca ou nenhuma provisão de serviços, com infraestrutura urbanística precária e baixos índices de desenvolvimento humano. Vários indicadores de carência sobrepostos em um mesmo local potencializam as chances de pessoas serem alvos dos agravos em questão e apontam as desigualdades sociais como um dos principais condicionantes ${ }^{7}$.

Por tudo, é urgente a necessidade de considerar as elevadas taxas de homicídios, mas sobretudo com o recorte do respectivo por contexto socioespacial que contribui para a sua ocorrência, para que se adote mais racionalidade na elaboração de políticas públicas e na realização de ações de prevenção ao citado agravo, para que se levem em consideração, para além de mudanças pontuais, transformações societárias que diminuam a desigualdade e possam, de alguma forma, repercutir positivamente, sobretudo nas capitais e nos grandes centros urbanos, onde o problema parece ser mais grave.

No Brasil, os agravos por causas externas e, de modo particular, o homicídio doloso, bem como as características que o circunscrevem, têm assumido características próprias, sobretudo nos grandes centros urbanos e nas capitais, porquanto concentram-se entre os indivíduos não brancos, adultos jovens, pouco escolarizados e moradores de áreas periféricas, tal como foi observado neste estudo.

$\mathrm{Na}$ realidade, os aspectos ora mencionados integram uma realidade mais ampla, que diz respeito à desigualdade social, que tem contribuído para vitimar um sem número de indivíduos por homicídio doloso, particularmente nos aglomerados subnormais, as áreas periféricas e de favelas, que historicamente carecem da presença mais efetiva do Estado para prover condições mínimas de cidadania, como saneamento, trabalho digno, educação e assistência social.

Crê-se que, embora de forma incipiente, as poucas políticas públicas sociais são mais eficazes entre os brancos, quando se compara com a eficácia alcançada entre os não brancos, cuja ocorrência de homicídio doloso, particularmente, só tem aumentado, em detrimento da redução, ainda que por vezes discreta, ocorrida no primeiro grupamento populacional. Assim, esse fato pode contribuir para que raça/cor seja um aspecto preditivo deste agravo em questão. O que se coloca, portanto, é a própria dignidade da vida humana, seja ela qual for.

O estudo apresenta a limitação de trabalhar com dados ecológicos, os quais não permitem a individualização das análises, dificultando a compreensão mais aprofundada de certas inferências. Ademais, a predominância do homicídio entre os não brancos pode estar associada apenas a aspectos socioeconômicos e não necessariamente a raça/cor, o que não pode ser melhor explicitado neste estudo. Por fim, outro aspecto limitante foi a impossibilidade de captação do endereço de residência de $26 \%$ das vítimas do agravo em questão, o que pode ter comprometido a realização dos mapas, através da geolocalização, e as análises que deles depreenderam-se. A diferença entre os dados aqui apresentados e aqueles disponibilizados pelo Sistema de Informação de Mortalidade podem divergir minimamente, porquanto após o envio destes mesmos dados por todas as Secretarias Municipais e Estaduais ao Ministério da Saúde, não é raro que isso implique em algumas alterações em virtude de correções realizadas, inclusive de redistribuição dos óbitos pelo local de residência. 


\section{AGRADECIMENTOS}

Os autores agradecem a Coordenação de Aperfeiçoamento de Pessoal de Nível Superior (CAPES) pelo apoio concedido e a Cícero Fidelis da Silva Neto, do Instituto Nacional do Semiárido, da Universidade Federal de Campina Grande, por sua importante contribuição na elaboração das figuras deste artigo.

\section{REFERÊNCIAS}

1. Bastos MJRP, Pereira JA, Smarzaro DC, Costa EF, Bossanel RCL, Oliosa DMS, et al. Ecological analysis of acidentes and lethal violence in Vitória, Southeastern Brazil. Rev Saude Publica. 2009;43(1):123-32. http:// dx.doi.org/10.1590/S0034-89102009000100016. PMid:19169584.

2. Borges LS, Alencar HM. Violence in the brasilian scenario: risk factores of adolecents facing a contemporary reality. J Hum Growth Dev. 2015;25(2):194-203. http://dx.doi.org/10.7322/jhgd.103015.

3. Cerqueira D, Bueno RSLS, Valencia LI, Hanashiro O, Machado PHG, Lima AS. Atlas da violência 2017. Rio de Janeiro: IPEA; 2017. 76 p.

4. Escobar-Córdoba F, Acero-González AR, Folino JO. Homicidas juveniles en Bogotá, estudio de grupos focales. Rev Fac Med. 2015;63(3):389-98. http://dx.doi.org/10.15446/revfacmed.v63n3.50632.

5. Lima ALB, Lima KC, Maia LTS, Oliveira TC. Tendência crescente de violência homicida na região metropolitana de Natal-RN, Brasil. Revista Ciência Plural. 2015;1(2):19-28.

6. Rocha GG, Nunes BP, Silva EF, Wehrmeister FC. Análise temporal da mortalidade por homicídios e acidentes de trânsito em Foz do Iguaçu, 2000-2010. Epidemiol Serv Saude. 2016;25(2):323-30. PMid:27869950.

7. Kleinschmitt SC, Wadi YM, Staduto JA. Analise espacial dos homicídios no estado do Paraná. Redes. 2012;17(3):257-90.

8. Minayo MCS, Constantino P. An ecosysthemic view of homicide. Cien Saude Colet. 2012;17(12):3269-78 http://dx.doi.org/10.1590/S1413-81232012001200012. PMid:23175403.

9. Zilli LPO. O "mundo do crime" e a "lei da favela": aspectos simbólicos da violência de gangues na região metropolitana de Belo Horizonte. Etnografica. 2015;19(3):463-87. http://dx.doi.org/10.4000/ etnografica.4074.

10. Nardi SMT, Paschoal JAA, Pedro HSP, Paschoal VDA, Sichieri EP. Geoprocessamento em Saúde Pública: fundamentos e aplicações. Rev Inst Adolfo Lutz. 2013;72(3):185-91. http://dx.doi.org/10.18241/007398552013721562.

11. Santos SM, Santos WVS. Introdução à estatística espacial para a saúde pública. Brasília: Ministério da Saúde; 2007. 120 p.

12. Nery MB, Peres MFT, Cardia N, Vicentin D, Adorno S. Regimes espaciais: dinâmica dos homicídios dolosos na cidade de São Paulo entre 2000 e 2008. Rev Panam Salud Publica. 2012;32(6):405-12. http://dx.doi. org/10.1590/S1020-49892012001400003. PMid:23370183.

13. Fuentes Flores C, Sánchez Salinas O. Contexto sociodemografico de los homicídios en Mexico D.F.: un análisis espacial. Rev Panam Salud Publica. 2015;38(6):450-6. PMid:27440092.

14. Tourinho FC Fo. Manual de processo penal. 16. ed. São Paulo: Saraiva; 2013. 1042 p.

15. Medeiros CN, Pinheiro FSA, Marques e Sousa G, Pinheiro DRC. Correlações espaciais entre ocorrências de homicídios e concentração de aglomerados subnormais em Fortaleza, Ceará. Revista GeoUECE. 2013;2(1):92-110.

16. Instituto Brasileiro de Geografia e Estatística - IBGE. Censo 2010: aglomerados subnormais. Rio de Janeiro: IBGE; 2010. 251 p.

17. Secretti T. Distribuição dos homicídios em Porto Alegre, Rio Grande do Sul, 2007: contexto sócio espacial e fatores determinantes [dissertação]. Porto Alegre: Programa de Pós-graduação em Epidemiologia, Universidade Federal do Rio Grande do Sul; 2009.

18. Tavares R, Catalan VDB, Romano PMM, Melo EM. Homicídios e vulnerabilidade social. Cien Saude Colet. 2016;21(3):923-34. http://dx.doi.org/10.1590/1413-81232015213.12362015. PMid:26960104.

19. Costa AC, Marguti BO. Atlas de vulnerabilidade social nos municípios brasileiros. Brasília: IPEA; 2015. 77 p.

20. Carvalho AX, Silva GD, Almeida GR Jr, Albuquerque PH. Taxas bayesianas para o mapeamento de homicídios nos municípios brasileiros. Cad Saude Publica. 2012;28(7):1249-62. http://dx.doi.org/10.1590/S0102311X2012000700004. PMid:22729256. 
21. Duarte EC, Garcia LP, Freitas LRS, Mansano NH, Monteiro RA, Ramalho WM. Associação ecológica entre características dos municípios e o risco de homicídios em homens adultos de 20-39 anos de idade no Brasil, 1999-2010. Cien Saude Colet. 2012;17(9):2259-68. http://dx.doi.org/10.1590/S1413-81232012000900008. PMid:22996878.

22. Soares AM Fo. Homicide victimization according to racial characteristics in Brazil. Rev Saude Publica. 2011;45(4):1-10. PMid:21739076.

23. Alves WA, Correia DS, Barbosa LLB, Lopes LM, Melânia MIASM. Violência letal em Maceió - AL: estudo descritivo sobre homicídios, 2007-2012. Epidemiol Serv Saude. 2014;23(4):731-40. http://dx.doi. org/10.5123/S1679-49742014000400015.

24. Soares AM Fo, Souza MFM, Gazal-Carvalho C, Malta DC, Alencar AP, Silva MMA, et al. Análise da mortalidade por homicídios no Brasil. Epidemiol Serv Saude. 2007;16(1):7-18.

25. Barcellos C, Zaluar A. Homicides and territorial struggles in Rio de Janeiro favelas. Rev Saude Publica. 2014;48(1):94-102. http://dx.doi.org/10.1590/S0034-8910.2014048004822. PMid:24789642.

26. Maior MM, Candido GA. Vulnerabilidade socioeconômica: um estudo transversal para o município de João Pessoa - PB. Revista Principia. 2014;1(4):72-87.

27. Ramão FP, WadiYM. Espaço urbano e criminalidade violenta: análise da distribuição espacial dos homicídios no município de Cascavel/PR. Rev Sociol Polit. 2010;18(35):207-30. http://dx.doi.org/10.1590/S010444782010000100013.

28. Santos SM, Barcellos C. Abordagens espaciais na saúde pública. Brasília: Ministério da Saúde; 2006. 136 p. 